\title{
Improvement and Exploration of Junior Middle School Chemistry Experiment Teaching under the Concept of New Curriculum Standard
}

\author{
Yang Chengrong \\ The 14th Middle School of Fuling District of Chongqing, Chongqing, China, 400800
}

Keywords: junior middle school chemistry experiment; experimental teaching

\begin{abstract}
Chemistry is an indispensable subject in the junior high school curriculum system, and chemistry experiment is the foundation of chemistry. Students need to observe theoretical phenomena to consolidate theoretical knowledge. Under the concept of new curriculum standards, junior high school chemistry experiment teaching has received great attention. This paper simply introduces the developing situation of the junior middle school chemical experiment teaching, expounds the important role of experimental teaching for junior middle school chemistry education, and mainly explores the junior middle school chemical experiment teaching under the new curriculum standard, in order to promote the better development of junior middle school chemical experiment teaching, cultivate students' exploring consciousness, and improve the middle school chemistry knowledge skills.
\end{abstract}

\section{Introduction}

Chemical experiments are an indispensable part of chemistry teaching. Through chemistry experiments, students can master the principles of chemical knowledge and related knowledge of the reaction process more fully, and can also stimulate students' interest in learning and improve their learning ability. The use of experimental methods in chemistry teaching is much better than the theoretical knowledge. The junior high school chemistry experiment teaching under the new subject standard concept is very different from the traditional teaching method. It is the main purpose of changing the teacher teaching method and changing the student learning method. The chemistry experiment teaching is an effective way to realize the new curriculum standard ${ }^{[1]}$.

\section{The development status of junior middle school chemistry experiment teaching}

At present, China's chemistry experiment teaching has achieved some achievements in experimental functional aspects, but compared with foreign chemistry experiment teaching, there is still a certain gap in the realization of teaching functions. From the current education system, no matter from the current education system, the curriculum setting is still in the direction of teaching time, and can not meet the experiment-based teaching mode of chemistry course. Under the new curriculum standard concept, chemistry teaching reduces the proportion of the original concept and principle teaching, and increases the class time of chemistry experiment, and 31 demonstration 
experiments and 19 group experiments were listed, further emphasizing the importance of experiments in chemistry teaching.

\section{The important role of experimental teaching in the education of junior middle school}

\subsection{Extended student thinking}

The chemical experiment focuses on the individual hands-on practice and specific operation, and the junior high school students' thinking ability and exploration knowledge can be cultivated through the process of chemical experiments. Students have doubts about their true thinking, and human learning is rooted in personal thinking. Therefore, personal thinking and learning have strong interrelationships. When students participate in chemical experiments, they are the most inspiring individual thinking. The chemical teacher gives appropriate explanations and guidance in the key points, and then fully exercises the students' practical ability. Combine the test propositions, promote the hands-on practice of the students, and carefully observe the process and experimentation of the experiment, and reach the goal of extending the students' thinking ${ }^{[2]}$.

\subsection{Rich students know}

The teaching of the experiment is very different from the teaching of the theory of the classroom. It has obvious characteristics of being intuitive and active. For the junior high school students, the teaching of the experiment is more interesting. However, there are many kinds of instruments for chemical experiments, and the good intentions of junior high school students are stronger. If only the students look at the teacher's experiment and find interesting experiments, they will also have a strong interest in learning and hands-on practice. When the teacher provides experimental teaching for the students, it not only satisfies the students' good intentions and operational desires, but also succeeds in learning and gaining results in the experiment. From then on, the student's learning state is changed, and the student is changed to be active, so that the students have a strong desire to learn and actively develop self-learning. figure 1 shows the effect of junior high school chemistry experiment teaching under the new curriculum standard concept ${ }^{[3]}$.

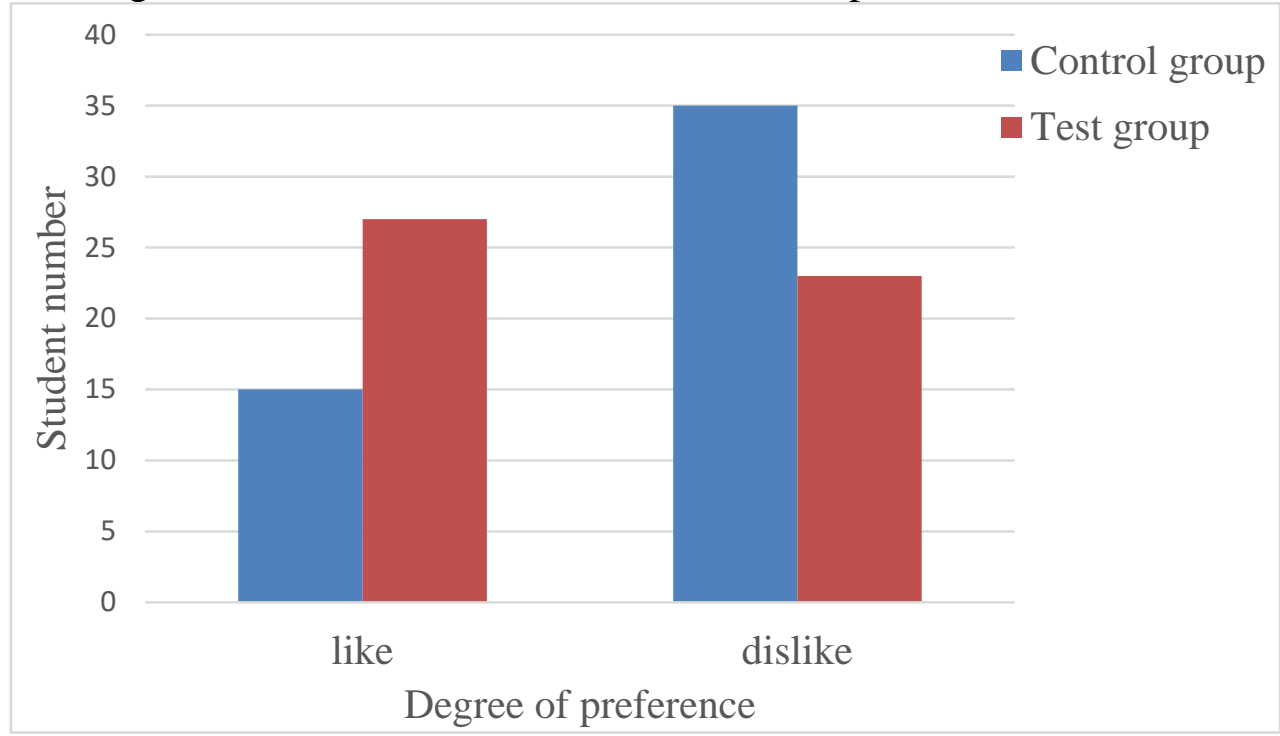

Figure 1 Students conduct inquiry chemistry experiment teaching 


\subsection{Break through the difficulty of learning knowledge}

The process of experimentation is to make the theory of knowledge straightforward and visually displayed. Through the teaching of chemical experiments, it is beneficial for students to break through the difficulties of knowledge, focus on learning, and quickly understand knowledge. And a part of the chemical knowledge and the concept of chemistry are derived from the evolution of the case. Use practical teaching to help students quickly acquire knowledge points and understand the definition and development rules. By simplifying the knowledge of the complex, it will improve the efficiency of the teaching of science.

\section{Changes in junior middle school chemistry experiment teaching under the new curriculum standard concept}

\subsection{Focus on experimental design}

In the traditional chemistry experiment teaching class, the students carry out the experimental operation according to the experimental steps in the textbook. The medicines and experimental instruments required for the experiment are also prepared by the teachers. Therefore, such chemistry experiment teaching lacks the cultivation of students' interest in learning. And thinking training can only be a simple skill training. The new curriculum standards have new requirements for junior high school chemistry teaching goals: students are required to design their own experimental programs, and conduct experiments under the guidance of group discussions or teachers. For example, in the experimental teaching of carbon dioxide in the "materials around us" in the ninth grade chemistry of the Shanghai Education Edition, several experimental topics were designed: inferring the decomposition products of malachite; Exploring the conditions of corroded iron products; Investigate the relative content changes in the air. And for the content of the experiment, combined with the experimental textbook design multiple content. Such chemistry experiment teaching can cultivate students' experimental ability and innovative spirit, and the students' thinking will gradually become more open under the guidance of teachers ${ }^{[4]}$.

\subsection{Focus on inquiry experiment}

An important method of scientific research is chemistry experiment. Under the new curriculum standard concept, junior middle school chemistry experiment teaching plays an important role in the cultivation of students' interest in learning, scientific morality and the development of scientific spirit. Traditional junior high school chemistry experiments are mainly based on experimental verification, but under the guidance of the new curriculum standards, junior high school chemistry experiments are more inclined to explore experiments. Under the guidance of the teacher, the students observe the questions, make their own assumptions and conjectures, and then use the experiment to prove the facts. After that, they summarize the conclusions, and the groups exchange and discuss each other. Finally, the teachers guide them to expand their thinking. Such an experimental process fully exerts the essence of experimental inquiry. The student's personal experience is enriched through inquiry experiments, and students will understand the process and methods of the experiment. The experiment of mass conservation law in the ninth grade chemistry book of Shanghai Education Edition is a typical case study. As shown in Figure 2, the experiment uses the gas produced by white phosphorus combustion in a closed environment to verify the law of conservation of mass. Ask a question when designing the experiment: Can you use other experimental materials for this experiment? Such as dilute hydrochloric acid and limestone. There are many exploratory experiments in the Shanghai Jiaotong junior high school chemistry textbooks, 
but it is worth noting that the verification process is full of inquiry, and the process of inquiry is inseparable from verification ${ }^{[5]}$.

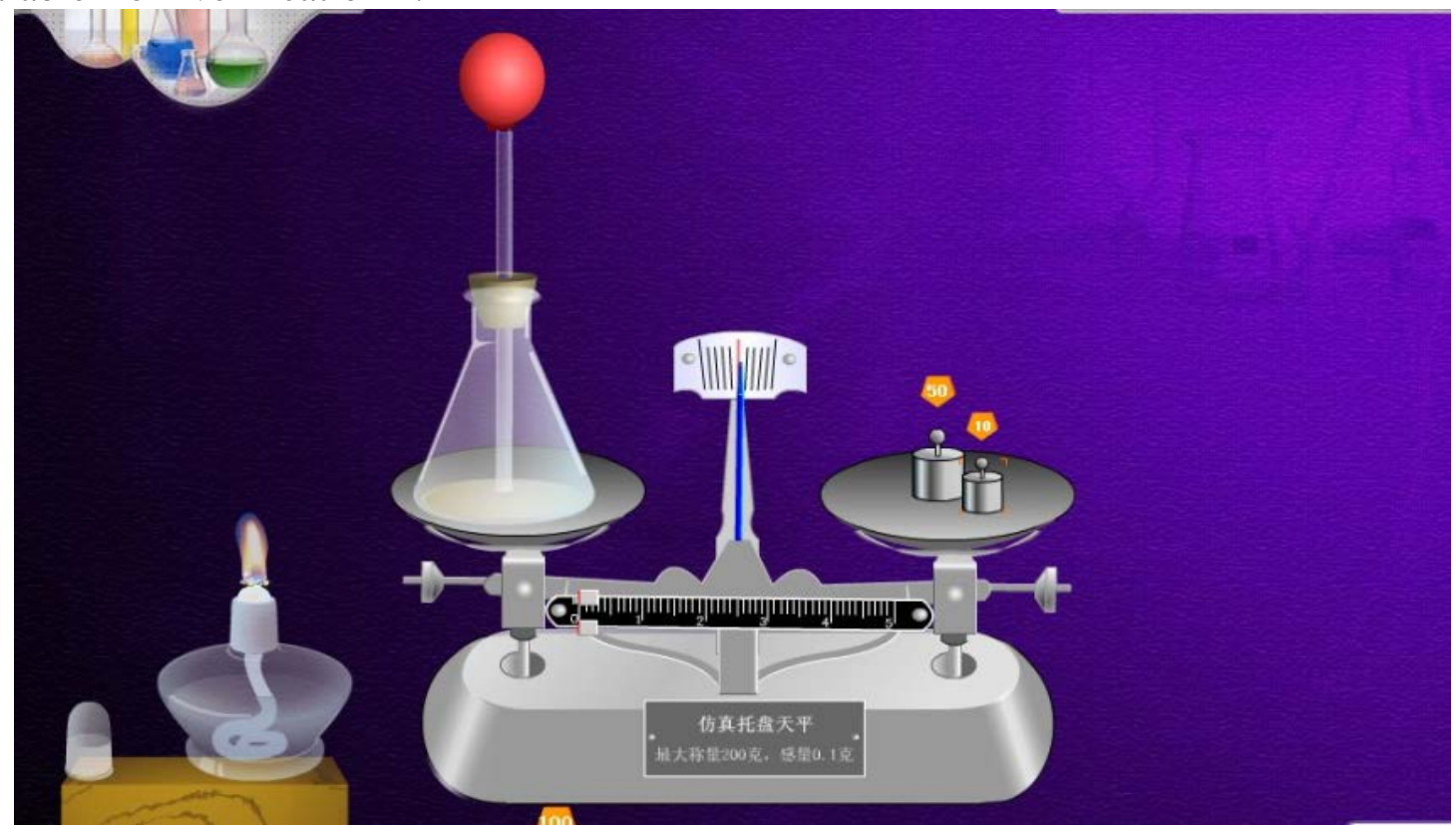

Figure 2 Determination of mass before and after white phosphorus combustion

\subsection{Close to student life}

The new curriculum standards require junior high school chemistry experiments to give students a very good understanding of the value and practicality of knowledge. Through the chemistry experiment teaching, the distance between chemistry and students is brought closer. Nowadays, the development of society and people's daily life are inseparable from chemistry. Therefore, junior high school chemistry experiment teaching needs to give students a full understanding of the fact that chemistry is around us, so that students can feel the practicality of chemistry.

In the course of chemistry experiment teaching, teachers can use the textbook to design experiments that are related to the actual life of the students. For example, when learning the chapter "Materials around us", design "water purification experiment", "explore human exhalation" The difference between the gas and the inhaled air" and other experiments. This kind of experimental design can make students have more inquiry and curiosity about the subject of chemistry. Under the guidance of teachers, students can develop the habit of observing, discovering and verifying the things around them under the guidance of teachers. In this way, students will improve their comprehensive quality after a long period of study and exercise scientific literacy, which is more in line with the society's requirements for high-quality talents.

\section{Conclusions}

In general, under the requirements of the new curriculum reform standards, the experimental teaching in junior middle school has slowly turned into a highly exploratory teaching. This is not only a huge challenge in the teaching of chemical science, but also a change in the teaching of chemical science. Chemistry is itself inextricably linked to life. Studying chemistry enables students to have strong feelings towards nature and society, care about the development and change of nature and society, and promote the formation of their own spirit and ability of inquiry. Therefore, we must adhere to the direction of education reform, follow the trend of development in the times, and 
actively update the teaching and learning concepts, and continue to promote the development and advancement of science education.

\section{References}

[1] Chen Lijuan. Exploration and implementation of junior middle school chemistry experiment teaching under the new curriculum standard concept [D]. Inner Mongolia Normal University, 2010.

[2] Du Qingyan. A Brief Discussion on the Reform of Chemistry Experiment Teaching in Junior Middle School under the New Curriculum Standard[J]. Charisma China, 2010(22):235-235.

[3] Li Dianhua. Reforming the Chemistry Experiment Teaching of Rural Junior Middle School under the New Curriculum Standard[J]. Education Science: Citations, 2016(11): 00217-00217.

[4] Lu Weiqing. Improvement and Practice of Junior Middle School Chemistry Demonstration Experiment under the New Curriculum Standard[J]. New Curriculum Guide, 2014(5): 28-29.

[5] Liang Shenghua. Exploration and Implementation of Chemistry Experiment Teaching in Junior Middle School under the New Curriculum Standard Concept[J]. Zhiyin Inspirational, 2016(24). 